\title{
The association of idiopathic recurrent early pregnancy loss with polymorphisms in folic acid metabolism-related genes
}

\author{
Yunlei Cao $\cdot$ Zhaofeng Zhang $\cdot$ Yanmin Zheng $\cdot$ \\ Wei Yuan · Jian Wang $\cdot$ Hong Liang · \\ Jianping Chen $\cdot$ Jing Du $\cdot$ Yueping Shen
}

Received: 24 October 2013/Accepted: 27 March 2014/Published online: 12 April 2014

(c) Springer-Verlag Berlin Heidelberg 2014

\begin{abstract}
The aim of this study was to investigate the association between polymorphisms in folic acid metabolism-related genes and idiopathic recurrent early pregnancy loss (REPL). A prospective case-control study was performed on a cohort of 82 REPL patients and 166 healthy controls. Genotyping of methylenetetrahydrofolate reductase (MTHFR) C677T and A1298C was assessed by applying polymerase chain reaction for amplification followed by DNA sequencing, for methionine synthase reductase A66G, solute carrier family 19, member 1 (SLC19A1) G80A and C696T, and genotyping was done by utilizing the Sequenom MassARRAY system. The results revealed a significant association between MTHFR A1298C polymorphism and idiopathic REPL. Haplotype analysis indicated that the MTHFR 677C-MTHFR 1298C
\end{abstract}

Our study was done at NPFPC Laboratory of Contraception and Devices, Shanghai Institute of Planned Parenthood Research, 2140 Xietu Road, Shanghai 200032, China.

Y. Cao

Fudan University, 130 Dong'an Road, Shanghai 200032, China

Y. Cao - Z. Zhang $\cdot$ W. Yuan · J. Wang $\cdot$ H. Liang $\cdot$ J. Chen · J. Du

Institute of Reproduction and Development, Fudan University, Shanghai 200032, China

Y. Cao - Z. Zhang $\cdot$ W. Yuan $\cdot$ J. Wang $\cdot$ H. Liang $\cdot$ J. Chen J. Du ( $\triangle)$

NPFPC Laboratory of Contraception and Devices, Shanghai Institute of Planned Parenthood Research, 2140 Xietu Road, Shanghai 200032, China

e-mail: dujing42@126.com

Y. Zheng · Y. Shen $(\bowtie)$

Department of Biostatistics and Epidemiology, Public Health

School, Soochow University, Suzhou 215123, China

e-mail: shenyueping@suda.edu.cn allele combination was associated with REPL $(P<0.001)$. The MTHFR 677C-MTHFR 1298A and SLC19A1 80GSLC19A1 696C allele combinations had lower frequencies in patients with REPL, but with $P>0.05(P=0.093$ and $P=0.084$, respectively).

Keywords MTHFR - MTRR - SLC19A1 ·

Polymorphism $\cdot$ Homocysteine $\cdot$ Folic acid

\section{Introduction}

Recurrent early pregnancy loss (REPL) is usually defined as three or more consecutive spontaneous miscarriages before 20 gestational weeks; however, it has been redefined as two or more consecutive spontaneous miscarriages by the American Society for Reproductive Medicine (ASRM) (Coulam et al. 1997, 2013). It is a complex disease; both genetic and environmental factors contribute to its development. Approximately 2-4\% reproductive-aged women are suffering from this problem worldwide; the known etiologies of REPL include parental chromosome abnormalities, uterine anomalies, endocrinology disorders, immune disorders, thrombophilia, maternal infections and nutritional infections (Younis et al. 1997; Li et al. 2002; 2013). However, 40-55 \% of REPL with undetermined causes could not be detected by any available clinical and laboratory examinations. REPL as a multifactorial disorder is a relentless problem which may devastate the happiness of a family, and even lead to the breakdown of a family life. Meanwhile, this problem is challenging for the obstetricians.

Hyperhomocysteinemia (HHcy) has been reported to be an independent risk factor for many pregnancy-related disorders such as neural tube defects, placental abruption 
or infarction, preeclampsia and unexplained recurrent miscarriage (Wouters et al. 1993; Goddijn-Wessel et al. 1996; Ray and Laskin 1999; Wenstrom et al. 2000). Genetic and environmental factors including metabolism can result in homocysteine (Hcy) accumulation in plasma, subsequently, lead to the occurrence of HHcy. Genetic factor is mainly the reduction or deletion of Hcy metabolism-related enzyme activity such as methylenetetrahydrofolate reductase (MTHFR) and methionine synthase (MTR). MTHFR C667T and A1298C polymorphisms have been shown to affect the enzyme activity (Frosst et al. 1995; Weisberg et al. 1998), which may have an effect on the Hcy levels. Environmental factor (nutrient cofactors) includes Hcy metabolism cofactor, such as folate, vitamin $\mathrm{B}_{12}$ and $\mathrm{B}_{6}$. Folate and Hcy, the key molecules of one-carbon metabolism, are important for the maintenance of pregnancy (Yajnik and Deshmukh 2012). Folate is necessary for DNA synthesis, cell growth and division, and thus, it is essential for the rapidly growing fetal tissue and placenta during pregnancy (Taparia et al. 2007). Moreover, folate acts as a substrate or cofactor for many biologic reactions, including metabolism of several amino acids, transmethylation and transsulfuration (Hernandez-Diaz et al. 2000; Dasarathy et al. 2010). Hcy in the body has two metabolism pathways: one is converting into cysteine under the catalysis of cystathionine shrink synthase and cystathionine enzyme with cofactor vitamin $\mathrm{B}_{6}$ through the transsulfuration pathway, and the other is synthesizing methionine by transmethylation pathway with cofactor vitamin $\mathrm{B}_{12}$ and folate. Folate deficiencies lead to increased Hcy level, and the supplementation with folic acid and vitamin $B_{12}$ reduces the concentration of Hcy in the bloodstream (Miller et al. 1994; van Guldener and Stehouwer 2001). Hence, the balance between Hcy and folate is vital for normal pregnancy.

Many earlier studies described the relationship between MTHFR gene polymorphisms and RPL, but with conflict results (Cao et al. 2013; Nair et al. 2013). Recently, literatures firstly reported the association between other onecarbon metabolism genes methionine synthase reductase (MTRR) and solute carrier family 19, member 1 (SLC19A1) polymorphisms and RPL in other populations (Rah et al. 2012; Kim et al. 2013). Hence, we performed the study firstly in a Chinese population to examine the association between MTHFR C677T (rs1801133) and A1298C (rs1801131), MTRR A66G (rs1801394) and SLC19A1 G80A (rs1051266) and C696T (rs12659) polymorphisms and idiopathic REPL in order to seek genetic risk factors of REPL which maybe helpful to prevent or cure the problem.

\section{Materials and methods}

\section{Subjects}

The study consisted of 82 REPL women (mean \pm SD age, $28.43 \pm 3.89$ years; body mass index (BMI), $21.03 \pm 2.30 \mathrm{~kg} / \mathrm{m}^{2}$ ) with at least two consecutive pregnancy losses before 12-week gestational age as case and 166 pregnant women (mean \pm SD age, $28.10 \pm 3.59$ years; BMI, $20.04 \pm 2.27 \mathrm{~kg} / \mathrm{m}^{2}$ ) with no history of miscarriage was recruited as control subjects. Of 82 cases, 54 REPL women had supplemented folic acid (3 months before pregnancy and 3 months of pregnancy, $0.8 \mathrm{mg}$ each day.). The patients were enrolled from the Maternal and Child Health Center in Kunshan City, the First People's Hospital and the Second People's Hospital affiliated with Soochow University. Patients were identified and recruited when they visited the above-mentioned hospitals for repeated (two or more), consecutive unexplained terminations of pregnancy before 12 weeks of gestation or expulsions of a fetus weighing $<500 \mathrm{~g}$. Other inclusion criteria included an age between 20 and 40 years. Subjects with the following characteristics were excluded: anatomical disorders, endocrine disorders, autoimmune disorders or deficiencies in blood coagulation factors. One hundred and sixty-six pregnant women aged 20-39 years with no history of miscarriage were recruited as control subjects ( 2 for each case patient) with the following matching criteria: age ( \pm 2 years), gestational age $( \pm 1$ week) and residence (the same district). None of the controls had a history of pregnancy complications, miscarriage, still birth or preeclampsia, and none had given birth to a child who was small for gestational age. Written informed consent was obtained from all the participants before their enrollment in the study. The study was approved by the Ethics Committee of Soochow University.

Recurrent early pregnancy loss patients and controls were asked to provide information on demographic characteristics, lifestyle, obstetric history and other REPL risk factors using a structured questionnaire. In the following 2 weeks after the day of recruitment, anticoagulated peripheral blood samples were collected from 82 REPL cases and 166 health controls by vein puncture. All the blood samples were stored at $-80{ }^{\circ} \mathrm{C}$ until genomic DNA isolation was undertaken.

\section{Genotyping}

Genomic DNA was extracted from peripheral blood with anticoagulant with the QIA-amp DNA blood kit (QIAGEN, Hilden, Germany) following the manufactures' instructions. 
The MTHFR C677T and A1298C polymorphisms were detected by polymerase chain reaction (PCR) for amplification followed by DNA sequencing. Firstly, thirty cycles of amplification were performed on a Gene Amp PCR system 9700 (Applied Biosystems, Foster City, CA) in a $15 \mathrm{ul}$ reaction volume containing $10 \mathrm{ng}$ of DNA, $2.5 \mathrm{mM}$ $\mathrm{MgCl}_{2}, 0.2 \mathrm{mM}$ dNTP, 10 pmol forward primer, $10 \mathrm{pmol}$ reverse primer and $0.25 \mathrm{U}$ Taq DNA polymerase (Sigma, St. Louis, MO, USA). Each cycle consisted of $30 \mathrm{~s}$ at $94{ }^{\circ} \mathrm{C}$ for denaturation, $30 \mathrm{~s}$ at $57{ }^{\circ} \mathrm{C}$ for MTHFR C677T and $59{ }^{\circ} \mathrm{C}$ for MTHFR A1298C for annealing and $1 \mathrm{~min}$ at $72{ }^{\circ} \mathrm{C}$ for extension. The first cycle was preceded by an initial denaturation step $3 \mathrm{~min}$ at $94{ }^{\circ} \mathrm{C}$ and a single step of extension at $72{ }^{\circ} \mathrm{C}$ for $10 \mathrm{~min}$ followed by the last cycle. The following primers were used to amplify the MTHFR C677T region: forward 5'-CAGCCTGTGCGAGGA CGGT-3' and reverse 5'-CAGCCACTCACTGTTTTA-3'. The amplification of MTHFR A1298C was done using a sense primer $\left(5^{\prime}\right.$-GCTCCCTCTAGCCAATCCCT-3 $\left.{ }^{\prime}\right)$ and an antisense primer (5'-GACCAAAGAGTTACATCTACC G- $3^{\prime}$ ). Secondly, the preparation of DNA for sequencing included incubating PCR products with $0.1 \mathrm{U}$ shrimp alkaline phosphatase (Roche, Basel, Switzerland) and $0.5 \mathrm{U}$ exonuclease I (New England Biolabs Inc., Beverly, MA) $45 \mathrm{~min}$ at $37{ }^{\circ} \mathrm{C}$, and then heat inactivation $20 \mathrm{~min}$ at $85^{\circ} \mathrm{C}$. Thirdly, the PCR products were sequenced by using an ABI Prism BigDye Terminator Cycle Sequencing Kit, version 3.1 (Applied Biosystems, Foster city, CA). Finally, the sequences were analyzed by an ABI PRISM model 3100 DNA Sequencer (PE Applied Biosystems, PerkinElmer) to determine the genotypes of each sample. Both forward and reverse primers were used for sequencing; the concordance of the genotypes of each sample was $100 \%$.

The polymorphisms of MTRR A66G, SLC19A1 G80A and C696T were assayed by utilizing the Sequenom MassARRAY iPLEX Platform. The assay consists of an initial locus-specific PCR, followed by single-base extension using mass-modified dideoxynucleotide terminators of an oligonucleotide primer which immediately anneals upstream of the polymorphic site of interest. Using MALDI-TOF mass spectrometry, the distinct mass of the extended primer identifies the SNP allele (Gabriel et al. 2009).

\section{Statistical analysis}

Differences in the MTHFR, MTRR and SLC19A1 genotype or allele frequencies between case and control subjects were compared using the chi-square test. Unconditional logistic regression was used, when adjusted by BMI of female participants. Odds ratio (OR), adjusted odds ratio (AOR) and their $95 \%$ confidence intervals (CI) were estimated as a measure of the strength of the association
Table 1 Comparison of genotype and allele frequencies of MTHFR C677T, MTHFR A1298C, SLC19A1 G80A, SLC19A1 C696T, MTRR A66G polymorphisms between REPL patients and control subjects

\begin{tabular}{|c|c|c|c|c|}
\hline $\begin{array}{l}\text { Genotype } \\
\text { and allele }\end{array}$ & $\begin{array}{l}\text { Control } \\
(n=166)\end{array}$ & $\begin{array}{l}\text { Case } \\
(n=82)\end{array}$ & $\operatorname{AOR}(95 \% \mathrm{CI})$ & $P$ value \\
\hline \multicolumn{5}{|c|}{ MTHFR C677T } \\
\hline $\mathrm{CC}$ & $53(0.319)$ & $29(0.354)$ & 1.0 (ref) & - \\
\hline $\mathrm{CT}$ & $83(0.500)$ & $43(0.524)$ & $0.92(0.51-1.68)$ & 0.794 \\
\hline $\mathrm{TT}$ & $30(0.181)$ & $10(0.122)$ & $0.56(0.23-1.33)$ & 0.185 \\
\hline $\mathrm{CT}+\mathrm{TT}$ & & & $0.82(0.47-1.46)$ & 0.507 \\
\hline $\mathrm{C}$ & 189 (0.569) & $101(0.616)$ & 1.0 (ref) & - \\
\hline $\mathrm{T}$ & $143(0.431)$ & $63(0.384)$ & $0.79(0.54-1.17)$ & 0.246 \\
\hline \multicolumn{5}{|c|}{ MTHFR A1298C } \\
\hline AA & $132(0.795)$ & $49(0.598)$ & 1.0 (ref) & - \\
\hline $\mathrm{AC}$ & $31(0.187)$ & $31(0.378)$ & $2.58(1.40-4.74)^{\#}$ & 0.002 \\
\hline $\mathrm{CC}$ & $3(0.018)$ & $2(0.024)$ & $\begin{array}{l}2.00 \\
(0.32-12.47)\end{array}$ & 0.459 \\
\hline $\mathrm{AC}+\mathrm{CC}$ & & & $2.53(1.40-4.57)$ & 0.002 \\
\hline A & $295(0.889)$ & $129(0.787)$ & 1.0 (ref) & - \\
\hline $\mathrm{C}$ & $37(0.111)$ & $35(0.213)$ & $2.13(1.27-3.57)$ & 0.004 \\
\hline \multicolumn{5}{|c|}{ SLC19A1 G80A } \\
\hline GG & $45(0.271)$ & $22(0.268)$ & 1.0 (ref) & - \\
\hline GA & $94(0.566)$ & $37(0.451)$ & $0.86(0.45-1.64)$ & 0.643 \\
\hline AA & $27(0.163)$ & $23(0.281)$ & $1.84(0.85-3.98)$ & 0.122 \\
\hline $\mathrm{GA}+\mathrm{AA}$ & & & $1.08(0.59-1.99)$ & 0.807 \\
\hline G & $184(0.554)$ & $81(0.494)$ & 1.0 (ref) & - \\
\hline A & $148(0.446)$ & $83(0.506)$ & $1.31(0.89-1.93)$ & 0.165 \\
\hline \multicolumn{5}{|c|}{ SLC19A1 C696T } \\
\hline $\mathrm{CC}$ & $45(0.271)$ & $23(0.280)$ & 1.0 (ref) & - \\
\hline $\mathrm{CT}$ & $94(0.566)$ & $35(0.427)$ & $0.76(0.40-1.46)$ & 0.411 \\
\hline $\mathrm{TT}$ & $27(0.163)$ & $24(0.293)$ & $1.86(0.87-3.99)$ & 0.110 \\
\hline $\mathrm{CT}+\mathrm{TT}$ & & & $1.00(0.55-1.84)$ & 0.988 \\
\hline $\mathrm{C}$ & $184(0.554)$ & $81(0.494)$ & 1.0 (ref) & - \\
\hline $\mathrm{T}$ & $148(0.446)$ & $83(0.506)$ & $1.32(0.90-1.93)$ & 0.158 \\
\hline \multicolumn{5}{|c|}{ MTRR A66G } \\
\hline AA & $98(0.590)$ & $43(0.524)$ & 1.0 (ref) & - \\
\hline AG & $53(0.319)$ & $28(0.341)$ & $1.12(0.62-2.04)$ & 0.701 \\
\hline GG & $15(0.090)$ & $11(0.134)$ & $1.69(0.71-4.06)$ & 0.239 \\
\hline $\mathrm{AG}+\mathrm{GG}$ & & & $1.25(0.72-2.15)$ & 0.429 \\
\hline A & $249(0.750)$ & $114(0.695)$ & 1.0 (ref) & - \\
\hline $\mathrm{G}$ & $83(0.250)$ & $50(0.305)$ & $1.29(0.84-1.97)$ & 0.241 \\
\hline
\end{tabular}

Ref is the reference group (same as the follows)

AOR is adjusted odd ratio by body mass index of female participants

\# Significance level $\alpha=0.0167$ by Bonferroni correction

between REPL and polymorphisms in folic acid metabolism-related genes. Then studies were stratified according to the folic acid supplementation status (yes or no). HardyWeinberg equilibrium was tested by the use of the goodness-of-fit chi-square test. Statistics were observed with 
SPSS version 13.0 (SPSS Inc, Chicago, IL). The linkage disequilibrium statistics were computed using $\mathrm{D}^{\prime}$ and $r^{2}$ on Haploview Ver. 3.32 (Barrett et al. 2005). Haplotype distribution was estimated using the program UNPHASE (Dudbridge 2003). The comparisons of genotype and allele frequencies were performed on the online software SHEsis (http://202.120.7.14/analysis/myAnalysis.php) (Shi and He 2005). Genetic power was calculated using the Quanto (http://hydra.usc.edu/gxe). On the basis of prevalence of minor polymorphism in $20 \%$ of Asians in the general population and a ratio of two control subjects to 1 case, 82 REPL cases and 166 control subjects have $87 \%$ power to detect an OR of $2.0(b=87 \%, a=0.05)$. Significance levels were adjusted by Bonferroni correction to account for multiple testing. Linkage disequilibrium testing showed that MTHFR C677T/A1298C and SLC19A1 G80A/C696T SNPs each had a correlation of $>80 \%$ and could not be considered as independent tests. Bonferroni correction was therefore made for 3 SNPs where appropriate, and we decreased the significance level to $0.017(0.05 / 3)$ according to the Bonferroni correction (O'Callaghan et al. 2012).

\section{Results}

The genotype distributions of the five polymorphisms were all in Hardy-Weinberg equilibrium $(P>0.05)$. The genotypes and alleles frequencies were compared between case and control subjects, and the data were shown in Table 1. Significant differences in genotype distributions and allele frequencies between case and control group were observed in MTHFR A1298C polymorphism (AC/AA, $\mathrm{AOR}=2.58,95 \%$ CI $1.40-4.74, P=0.002 ; \mathrm{AC}+\mathrm{CC} /$ $\mathrm{AA}, \mathrm{AOR}=2.53,95 \%$ CI $1.40-4.57 P=0.002 ; \mathrm{C} / \mathrm{A}$, $\mathrm{OR}=2.13,95 \%$ CI 1.27-3.57, $P=0.004$, respectively). For the other polymorphisms, the allele frequencies of MTHFR C677T (T/C, $P=0.246)$, SLC19A1 G80A (A/G, $P=0.165), \quad$ SLC19A1 C696T $(\mathrm{T} / \mathrm{C}, \quad P=0.158)$ and MTRR A66G $(\mathrm{G} / \mathrm{A}, P=0.241)$ in REPL cases were similar to those in healthy controls. When the subjects were stratified according to the folic acid supplementation status (questionnaire: yes or no), the association between the REPL cases and healthy controls both with folic acid supplementation is consistent with the association between REPL cases and healthy controls both with none in MTHFR C677T and A1298C, MTRR A66G, SLC19A1 G80A and C696T polymorphisms (Table 2).

$\mathrm{D}^{\prime}$ and $r^{2}$ were calculated to assess the extent of linkage disequilibrium in combination of the SNPs. The pairwise $\mathrm{D}^{\prime}$ values were 0.813 and 0.959 for MTHFR and SLC19A1, respectively. We performed haplotype analyses of MTHFR C677T/A1298C and SLC19A1 A80G/C696T polymorphisms to investigate the allele combinations that exert synergistic effects on the risk of REPL (Table 3 ). Among the haplotypes of MTHFR C677T/MTHFR A1298C, the MTHFR 677C-MTHFR 1298C haplotypes were positively associated with REPL $(P<0.001)$. The MTHFR 677C-MTHFR 1298A and SLC19A1 80GSLC19A1 696C haplotypes had lower frequencies in patients with REPL, whereas $P$ values were $>0.05$ ( $P=0.093$ and $P=0.084$, respectively).

\section{Discussion}

In order to exclude the influence of confounding factors, adjusted odd ratio (AOR) by BMI of female participants was estimated as a measure of the strength of the association between polymorphisms and REPL; however, the women's BMI in case and control groups was different which may still have an effect of the results. Moreover, it is difficult to accommodate environmental factors, such as living habits and dietary habits in the study design. Hence, as with another study, there were certain limits in our study. Even so, the result demonstrated a strong association of MTHFR A1298C polymorphism and REPL $(P=0.002)$. Haplotype analysis revealed that the MTHFR 677C-MTHFR 1298C allele combination was positively associated with REPL $(P<0.001)$.

A successful pregnancy is dependent on normal maternal immunity, adequate placental circulation and fetal vasculature and hemostatic balance. Elevated Hcy levels had been shown to damage the vascular endothelium, resulting in placental vasculopathy and increasing the risk of hemostatic imbalance (Ray and Laskin 1999; Smits and Thien 1991). The balance between Hcy and folate has been linked to HHcy. HHcy is attributed to inadequate intake of folic acid and vitamins or physiologic variations in the efficiency of the enzymes participating in the one-carbon folate-metabolism pathway (Scholl and Johnson 2000). MTHFR enzyme is an important enzyme of the folate and Hcy metabolic pathway, which is involved in a number of physiologic processes such as affecting genome stability, imprinting, expression and maintenance of appropriate Hcy level in the blood (Stern et al. 2000; Reidy 1987). This makes the polymorphisms in encoding MTHFR enzyme gene an essential biomarker to evaluate the risk of REPL. Our finding is consistent with the latest study by Nair et al. (2012); they suggested a significant risk of pregnancy loss associated with MTHFR A1298C polymorphism. Furthermore, another study indirectly supported our finding (Klai et al. 2011). Klai et al. revealed that MTHFR A1298C polymorphism, but not MTHFR C677T polymorphism, has been associated with elevated Hcy levels and placental vasculopathies. To the best of our knowledge, MTHFR A1298C polymorphism in pregnancy loss patients has been 


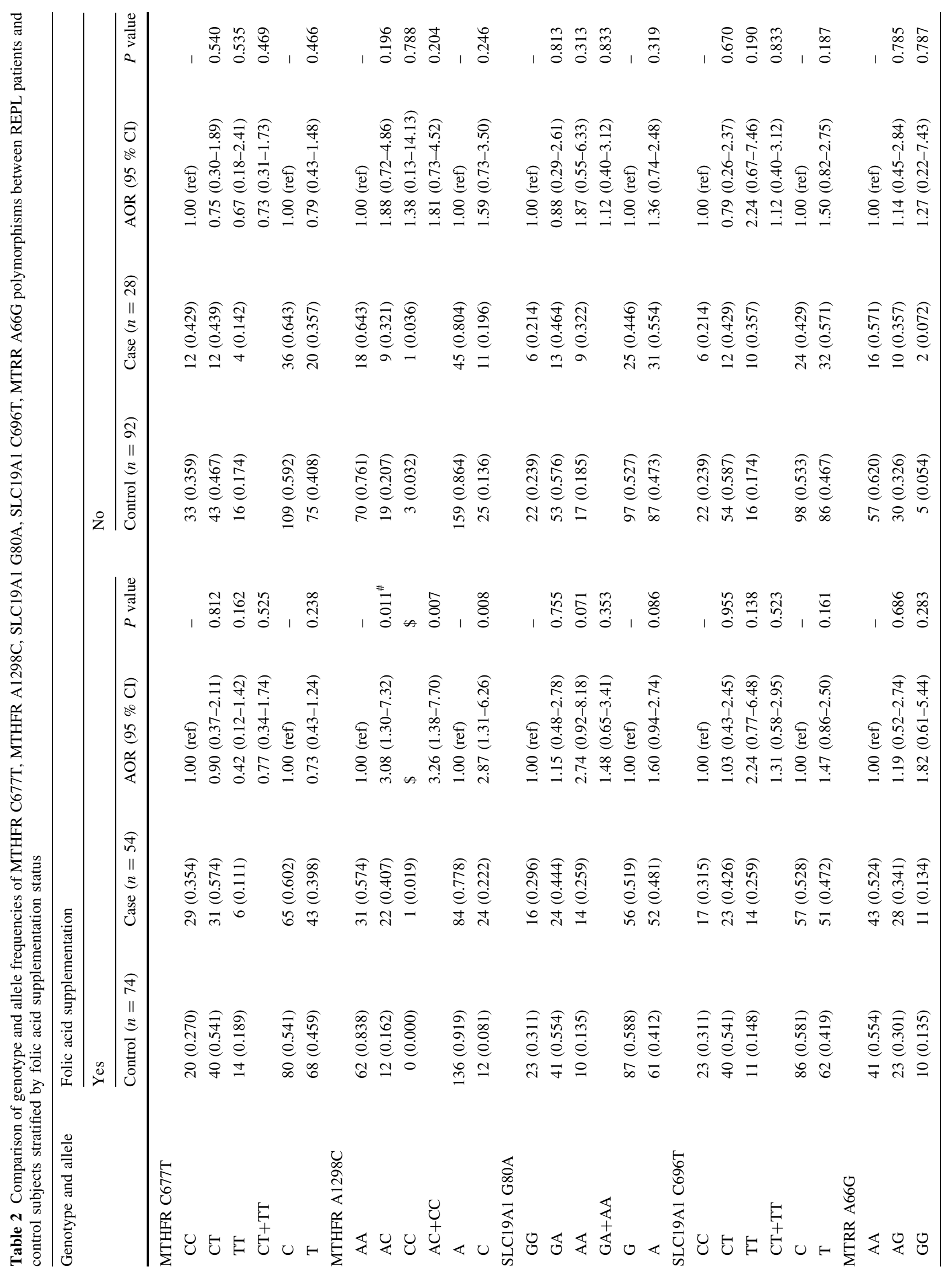




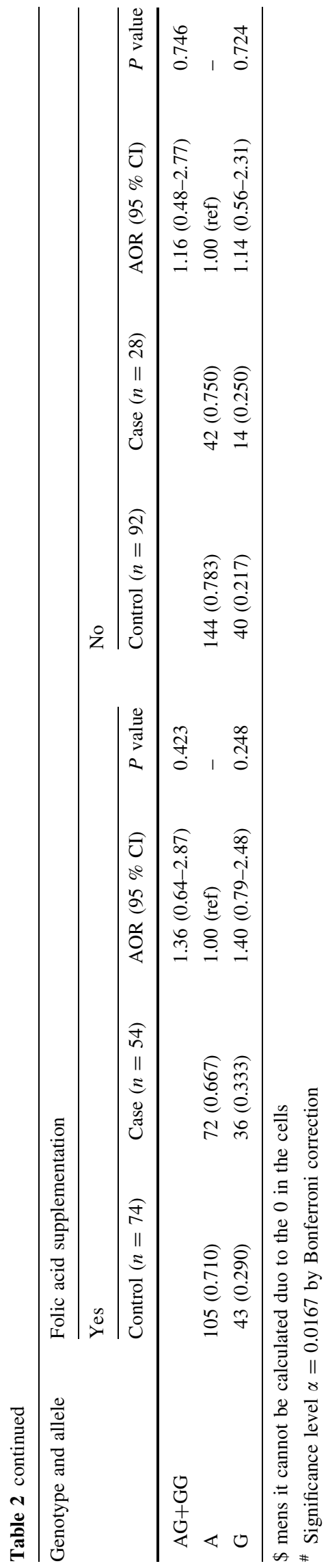

Table 3 Haplotypes frequencies of MTHFR C677T and A1298C, SLC19A1 G80A and C696T polymorphisms in patients with REPL and controls

\begin{tabular}{|c|c|c|c|c|}
\hline Haplotypes & $\begin{array}{l}\text { Control \% } \\
(n=166)\end{array}$ & $\begin{array}{l}\text { Case \% } \\
(n=82)\end{array}$ & OR $(95 \%$ CI $)$ & $P$ value \\
\hline \multicolumn{5}{|c|}{ MTHFR C677T/A1298C } \\
\hline $\mathrm{CA}$ & 0.474 & 0.402 & $0.72(0.49-1.06)$ & 0.093 \\
\hline $\mathrm{C} \mathrm{C}$ & 0.095 & 0.213 & $2.54(1.51-4.29)$ & $<0.001$ \\
\hline $\mathrm{T} \mathrm{A}$ & 0.414 & 0.384 & $0.86(0.58-1.26)$ & 0.432 \\
\hline $\mathrm{T} \mathrm{C}$ & 0.017 & 0.000 & - & - \\
\hline \multicolumn{5}{|c|}{ SLC19A1 G80A/C696T } \\
\hline A C & 0.003 & 0.025 & - & - \\
\hline A $\mathrm{T}$ & 0.443 & 0.481 & $1.167(0.80-1.70)$ & 0.420 \\
\hline $\mathrm{G} \mathrm{C}$ & 0.551 & 0.469 & $0.72(0.49-1.05)$ & 0.084 \\
\hline $\mathrm{G} \mathrm{T}$ & 0.003 & 0.025 & - & - \\
\hline
\end{tabular}

Frequency $<0.03$ in both control and case has been dropped

analyzed in white women, Tunisian, Turks and Indian populations (Hohlagschwandtner et al. 2003; Mtiraoui et al. 2006; Ozdemir et al. 2012; Nair et al. 2013). Presently, we analyzed this polymorphism in an ethnically diverse Chinese population. The significantly increased risk on REPL in the MTHFR A1298C mutation carriers was observed invariably, except the Hohlagschwandtner et al. study. All these indicated $\mathrm{C}$ allele and $\mathrm{AC}+\mathrm{CC}$ genotypes seem to be a risk factor of REPL. In our previous meta-analysis (Cao et al. 2013), we found a significant association of MTHFR C677T polymorphism with RPL, which is supported by several studies (Nelen et al. 1997; Unfried et al. 2002; Nair et al. 2012), In present study, we observed that MTHFR A1298C substitution increases the REPL risk. The inconsistent results between our previous meta-analysis and our present study may be attributed to the difference of gestational weeks used to define RPL in each study. Studies included in our meta-analysis had a large range of abortion gestational week; however, the REPL cases included in the present study were all women with at least two consecutive pregnancy losses before 12-week gestational age. As we all know that the cause of RPL in different stages of pregnancy is different, the inconsistent results can be explained. MTRR A66G and SLC19A1 G80A and C696T polymorphisms in RPL patients have been studied by Kim et al. and Rah et al. in Korean population, respectively, and no association was observed between MTRR A66G, SLC19A1 G80A and SLC19A1 C696T polymorphism with RPL (Rah et al. 2012; Kim et al. 2013). MTRR A66G is involved in onecarbon metabolism, but has not been studied extensively in RPL etiology. Considering the SLC19A1 gene encodes the RFC1 protein, it is plausible that polymorphism in SLC19A1 gene may interfere with the folate transporting by means of reduced SLC19A1 protein expression (De 
Marco et al. 2003; Relton et al. 2003). The effects of SLC19A1 G80A polymorphism on cellular folate intake remain uncertain (Whetstine et al. 2001; StanislawskaSachadyn et al. 2009); however, the G allele of G80A has been suggested as a risk factor for HHcy (Chango et al. 2000; Altmae et al. 2010), which is speculated to be associated with defective chorionic villous visualization in women with RPL (Nelen et al. 2000). In the study, our findings were consistent with previous ones. Stratified analysis showed no obvious difference in the distribution of genotype and allele between the REPL cases and health controls both in and no folic acid supplementation subgroup. From the results of analysis, we can only just conclude that folic acid supplementation status is not related to the distribution of polymorphisms in folic acid metabolism-related genes between REPL case and healthy control, but cannot conclude that folic acid supplementation status or folic acid is not a protection factor in REPL. In this study, we just analyzed according to the folic acid supplementation status, but the precise folate level in participants was not known. Moreover, our daily diet also contains certain folic acid; however, it is difficult for us to take it into account, because everyone's diet habits are different. Therefore, the patients with folic acid supplementation are not equal to normal or high folic acid levels; on the contrary, the patients without folic acid supplementation cannot reveal low folic acid levels in blood. Hence, whether folic acid protects against REPL should be studied in further studies by measuring the precise folate concentrations in participants' blood. So, further studies are warranted to investigate the effects of folate status on pregnancy loss in combination with folate-metabolism gene polymorphisms.

In conclusion, our findings suggest that polymorphism in MTHFR A1298C was obviously associated with idiopathic REPL. The MTHFR 677C-MTHFR 1298C haplotype was positively associated with REPL $(P<0.001)$. The MTHFR 677C-MTHFR 1298A and SLC19A1 80G-SLC19A1 696C allele combinations had lower frequencies in patients with REPL $(P=0.093$ and $P=0.084)$, suggesting a protective nature on idiopathic REPL, which can be developed as new biomarkers to evaluate the risk of REPL. Additionally, folic acid supplementation can be a protective factor on REPL. However, the underlying mechanism of polymorphisms in folic acid metabolism-related genes in the development of REPL has not been demonstrated, so further studies are warranted to investigate the effect of polymorphisms in folate or Hcy and the folate-metabolism pathways.

Acknowledgments We would like to thank all the participants for providing blood samples. This work was supported by The Knowledge Innovation Program in Chinese Academy of Sciences (No. KSCX2-EW-R-06) to YLW and the National Basic Research Program of China (973 program, 2010CB529505).
Conflict of interest The authors declared no potential conflicts of interest with respect to the research, authorship and publication of this article.

\section{References}

Altmae S, Stavreus-Evers A, Ruiz JR, Laanpere M, Syvanen T, Yngve A et al (2010) Variations in folate pathway genes are associated with unexplained female infertility. Fertil Steril 94(1):130-137

Barrett JC, Fry B, Maller J, Daly MJ (2005) Haploview: analysis and visualization of $\mathrm{LD}$ and haplotype maps. Bioinformatics 21(2):263-265

Cao YL, Xu JH, Zhang ZF, Huang XL, Zhang AP, Wang J et al (2013) Association study between methylenetetrahydrofolate reductase polymorphisms and unexplained recurrent pregnancy loss: a meta-analysis. Gene 514(2):105-111

Chango A, Emery-Fillon N, de Courcy GP, Lambert D, Pfister M, Rosenblatt DS et al (2000) A polymorphism (80G- $>$ A) in the reduced folate carrier gene and its associations with folate status and homocysteinemia. Mol Genet Metab 70(4):310-315

Coulam CB, Clark DA, Beer AE, Kutteh WH, Silver R, Kwak J et al (1997) Current clinical options for diagnosis and treatment of recurrent spontaneous abortion. Clinical guidelines recommendation committee for diagnosis and treatment of recurrent spontaneous abortion. Am J Reprod Immunol 38(2):57-74

Dasarathy J, Gruca LL, Bennett C, Parimi PS, Duenas C, Marczewski $S$ et al (2010) Methionine metabolism in human pregnancy. Am J Clin Nutr 91(2):357-365

De Marco P, Calevo MG, Moroni A, Merello E, Raso A, Finnell RH et al (2003) Reduced folate carrier polymorphism $(80 \mathrm{~A}->\mathrm{G})$ and neural tube defects. Eur J Hum Genet 11(3):245-252

Dudbridge F (2003) Pedigree disequilibrium tests for multilocus haplotypes. Genet Epidemiol 25(2):115-121

Frosst P, Blom HJ, Milos R, Goyette P, Sheppard CA, Matthews RG et al (1995) A candidate genetic risk factor for vascular disease: a common mutation in methylenetetrahydrofolate reductase. Nat Genet 10(1):111-113

Gabriel S, Ziaugra L, Tabbaa D (2009) SNP genotyping using the Sequenom MassARRAY iPLEX platform. Curr Protoc Hum Genet 2:2-12

Goddijn-Wessel TA, Wouters MG, van de Molen EF, Spuijbroek MD, Steegers-Theunissen RP, Blom HJ et al (1996) Hyperhomocysteinemia: a risk factor for placental abruption or infarction. Eur J Obstet Gynecol Reprod Biol 66(1):23-29

Hernandez-Diaz S, Werler MM, Walker AM, Mitchell AA (2000) Folic acid antagonists during pregnancy and the risk of birth defects. N Engl J Med 343(22):1608-1614

Hohlagschwandtner M, Unfried G, Heinze G, Huber JC, Nagele F, Tempfer C (2003) Combined thrombophilic polymorphisms in women with idiopathic recurrent miscarriage. Fertil Steril 79(5):1141-1148

Kim JH, Jeon YJ, Lee BE, Kang H, Shin JE, Choi DH et al (2013) Association of methionine synthase and thymidylate synthase genetic polymorphisms with idiopathic recurrent pregnancy loss. Fertil Steril 99(6):1674-1680

Klai S, Fekih-Mrissa N, El Housaini S, Kaabechi N, Nsiri B, Rachdi $R$ et al (2011) Association of MTHFR A1298C polymorphism (but not of MTHFR C677T) with elevated homocysteine levels and placental vasculopathies. Blood Coagul Fibrinolysis 22(5):374-378

Li TC, Makris M, Tomsu M, Tuckerman E, Laird S (2002) Recurrent miscarriage: aetiology, management and prognosis. Hum Reprod Update 8(5):463-481 
Miller JW, Nadeau MR, Smith D, Selhub J (1994) Vitamin B-6 deficiency vs folate deficiency: comparison of responses to methionine loading in rats. Am J Clin Nutr 59(5):1033-1039

Mtiraoui N, Zammiti W, Ghazouani L, Braham NJ, Saidi S, Finan RR et al (2006) Methylenetetrahydrofolate reductase C677T and A1298C polymorphism and changes in homocysteine concentrations in women with idiopathic recurrent pregnancy losses. Reproduction 131(2):395-401

Nair RR, Khanna A, Singh K (2012) MTHFR C677T polymorphism and recurrent early pregnancy loss risk in north Indian population. Reprod Sci 19(2):210-215

Nair RR, Khanna A, Singh R, Singh K (2013) Association of maternal and fetal MTHFR A1298C polymorphism with the risk of pregnancy loss: a study of an Indian population and a metaanalysis. Fertil Steril 99(5):1311-1318

Nelen WL, Steegers EA, Eskes TK, Blom HJ (1997) Genetic risk factor for unexplained recurrent early pregnancy loss. Lancet 350(9081):861

Nelen WL, Bulten J, Steegers EA, Blom HJ, Hanselaar AG, Eskes TK (2000) Maternal homocysteine and chorionic vascularization in recurrent early pregnancy loss. Hum Reprod 15(4):954-960

O'Callaghan ME, Maclennan AH, Gibson CS, McMichael GL, Haan EA et al (2012) Fetal and maternal candidate single nucleotide polymorphism associations with cerebral palsy: a case-control study. Pediatrics 129(2):414-423

Ozdemir O, Yenicesu GI, Silan F, Koksal B, Atik S, Ozen F et al (2012) Recurrent pregnancy loss and its relation to combined parental thrombophilic gene mutations. Genet Test Mol Biomarkers 16(4):279-286

Practice Committee of American Society for Reproductive Medicine (2013) Definitions of infertility and recurrent pregnancy loss: a committee opinion. Fertil Steril 99(1):63

Rah H, Choi YS, Jeon YJ, Choi Y, Cha SH, Choi DH et al (2012) Solute Carrier Family 19, member 1 (SLC19A1) polymorphisms $(-43 \mathrm{~T}>\mathrm{C}, 80 \mathrm{G}>\mathrm{A}$, and $696 \mathrm{C}>\mathrm{T})$, and haplotypes in idiopathic recurrent spontaneous abortion in a Korean population. Reprod Sci 19(5):513-519

Ray JG, Laskin CA (1999) Folic acid and homocyst(e)ine metabolic defects and the risk of placental abruption, pre-eclampsia and spontaneous pregnancy loss: a systematic review. Placenta 20(7):519-529

Reidy JA (1987) Folate- and deoxyuridine-sensitive chromatid breakage may result from DNA repair during G2. Mutat Res 192(3):217-219

Relton CL, Wilding CS, Jonas PA, Lynch SA, Tawn EJ, Burn J (2003) Genetic susceptibility to neural tube defect pregnancy varies with offspring phenotype. Clin Genet 64(5):424-428

Scholl OT, Johnson WG (2000) Folic acid: influence on the outcome of pregnancy. Am J Clin Nutr 71(5 Suppl):1295S-1303S
Shi YY, He L (2005) SHEsis, a powerful software platform for analyses of linkage disequilibrium, haplotype construction, and genetic association at polymorphism loci. Cell Res 15(2):97-98

Smits P, Thien T (1991) Hypertension. Risk factor in heart and vascular diseases. Ned Tijdschr Tandheelkd 98(11):439-442

Stanislawska-Sachadyn A, Mitchell LE, Woodside JV, Buckley PT, Kealey C, Young IS et al (2009) The reduced folate carrier (SLC19A1) c.80G $>$ A polymorphism is associated with red cell folate concentrations among women. Ann Hum Genet $73(\mathrm{Pt}$ 5):484-491

Stern LL, Mason JB, Selhub J, Choi SW (2000) Genomic DNA hypomethylation, a characteristic of most cancers, is present in peripheral leukocytes of individuals who are homozygous for the C677T polymorphism in the methylenetetrahydrofolate reductase gene. Cancer Epidemiol Biomarkers Prev 9(8):849-853

Taparia S, Gelineau-van Waes J, Rosenquist TH, Finnell RH (2007) Importance of folate-homocysteine homeostasis during early embryonic development. Clin Chem Lab Med 45(12):1717-1727

Unfried G, Griesmacher A, Weismuller W, Nagele F, Huber JC, Tempfer CB (2002) The C677T polymorphism of the methylenetetrahydrofolate reductase gene and idiopathic recurrent miscarriage. Obstet Gynecol 99(4):614-619

van Guldener C, Stehouwer CD (2001) Homocysteine-lowering treatment: an overview. Expert Opin Pharmacother 2(9):1449-1460

Weisberg I, Tran P, Christensen B, Sibani S, Rozen R (1998) A second genetic polymorphism in methylenetetrahydrofolate reductase (MTHFR) associated with decreased enzyme activity. Mol Genet Metab 64(3):169-172

Wenstrom KD, Johanning GL, Owen J, Johnston KE, Acton S, Tamura T (2000) Role of amniotic fluid homocysteine level and of fetal 5, 10-methylenetetrahydrofolate reductase genotype in the etiology of neural tube defects. Am J Med Genet 90(1):12-16

Whetstine JR, Gifford AJ, Witt T, Liu XY, Flatley RM, Norris M et al (2001) Single nucleotide polymorphisms in the human reduced folate carrier: characterization of a high-frequency G/A variant at position 80 and transport properties of the His(27) and $\operatorname{Arg}(27)$ carriers. Clin Cancer Res 7(11):3416-3422

Wouters MG, Boers GH, Blom HJ, Trijbels FJ, Thomas CM, Borm GF et al (1993) Hyperhomocysteinemia: a risk factor in women with unexplained recurrent early pregnancy loss. Fertil Steril 60(5):820-825

Yajnik CS, Deshmukh US (2012) Fetal programming: maternal nutrition and role of one-carbon metabolism. Rev Endocr Metab Disord 13(2):121-127

Younis JS, Ohel G, Brenner B, Ben Ami M (1997) Familial thrombophilia-the scientific rationale for thrombophylaxis in recurrent pregnancy loss. Hum Reprod 12(7):1389-1390 